\title{
Meslek Yüksekokulu Son Sınıf Öğrencilerinin Uzamsal Yeteneklerinin İncelenmesi ${ }^{1}$
}

\section{Investigation of Spatial Abilities of Final Year Students in Vocational School}

\author{
Ali ìssan BENZER², Bünyamin YILDIZ ${ }^{3}$
}

\section{Öz}

Bu araştırmanın amacı, son sınıf meslek yüksekokulu öğrencilerinin uzamsal yeteneklerini program ve cinsiyet değişkenleri açısından incelemektir. Araştırmada veri toplama aracı olarak "Purdue Uzamsal Görselleştirme: Döndürme (ROT) Testi" kullanılmıştır. Araştırmanın örneklemini bir devlet meslek yüksekokulunun farklı programlarında öğrenim görmekte olan 102 son sınıf öğrencisi oluşturmuştur. Araştırma, nicel araştırma desenlerinden tarama deseni olarak planlanmıştır. Verilerin analizinde bağımsız gruplar t-testi ve tek yönlü varyans analizi kullanılmıştır. Yapılan analizler sonucu elde edilen bulgulara göre öğrencilerin uzamsal yetenek puanlarının yeterli düzeyde olmadıkları, teknik programlarda okuyan öğrencilerin uzamsal yetenek puanlarının sosyal programlarda okuyan öğrencilerin puanlarından anlamlı olarak daha yüksek olduğu sonucuna ulaşılmıştır. Ayrıca teknik ve sosyal programlar kendi içlerinde bağımsız olarak değerlendirildiğinde uzamsal yetenek puanlarında cinsiyet açısından anlamlı bir farklılık görülmemiştir.

Anahtar Kelimeler: Meslek yüksekokulu, mesleki eğitim, uzamsal görselleştirme, uzamsal yetenek, zihinsel döndürme

\section{Abstract}

The aim of this study was to investigate the spatial abilities of the final year students of vocational school in terms of program and gender. "The Purdue Visualization of Rotations (ROT) test" was used as a data collection tool in the study. The sample of the study consisted of 102 final year students studying in different programs of a state vocational school. The research was carried out as a survey design which is one of the quantitative research designs. The independent samples t-test and one-way ANOVA analysis were used to analyse the data. According to the results of the analyses, it was revealed that students' spatial ability test scores were not sufficient and the spatial ability scores of students in technical programs were significantly higher than the scores of students in the social programs. In addition, when the technical and social programs were evaluated independently within themselves, there was no significant difference in spatial ability scores in terms of gender.

Keywords: Mental rotation, spatial ability, spatial visualization, vocational education, vocational school 


\section{Extended Abstract}

Introduction: Vocational schools are an important complement of vocational and technical education system in Turkey and the aim of the establishment of vocational schools is to train qualified intermediate staffs required by industry, trade and service sectors (Şahin and FIndık, 2008). One of the objectives of vocational training is to educate students as competent individuals in their fields. The students in vocational schools should have some cognitive skills in order to be successful both in their school and professional life. Especially for those who work in technical fields, they need to have advanced spatial ability to be successful in their professional and academic lives (Alias, Black and Gray, 2002; Rafi, Samsudin and Said, 2008; Sorby, 1999). Spatial ability is an important factor not only for success in certain occupational fields but also for daily life and school success (Yılmaz, 2009). Spatial ability is a set of mental skills related to understanding, manipulating, rearranging and interpreting relations visually (Tartre, 1990). According to Gardner (2011), who introduced the theory of multiple intelligences, there are eight types of intelligence. He argued that one of eight intelligence types is visual-spatial intelligence. Gardner (2011) considered spatial ability as a kind of intelligence.

According to the literature, there are many factors which affect spatial ability. Gender is one of the most examined factors in studies on spatial ability differences. Many studies have been conducted to investigate whether there is a difference in spatial ability scores in terms of gender variable. The majority of studies on gender differences in spatial ability reported that there was significant difference in spatial ability scores in favor of male participants. Some studies reported that there was no significant difference in terms of gender.

As a result of the literature review, it was not found any study that investigated the spatial abilities of vocational school students in the national literature. When the studies on spatial ability for university students are examined, it was seen that the sample of the studies in the national literature generally consisted of teacher candidates, while the sample of the studies in the international literature consisted of students studying in the field of engineering and science besides the teaching candidates. It is thought that this study which was conducted for vocational school students will contribute to filling the gap in the literature. The aim of this study was to investigate the spatial abilities of final year students studying in vocational school. The problem of the study was determined as "What are the spatial ability levels of the final year students studying in different programs of a state vocational school?" In this context, it was focused on the following sub-problems:

- Is there a significant difference in the spatial ability scores of students studying in technical programs and social programs?

- Is there a significant difference in the spatial ability scores in terms of gender?

- Is there a significant difference in the spatial ability scores in terms of program?

Method: The research was carried out as a survey design which is one of the quantitative research methods. The survey design is a research method that aims to describe a situation that has existed in the past or is still present (Karasar, 2016). The sample of the study consisted of 102 final year students studying in five different programs (computer aided design and animation, computer technology, internet and network technologies, office management and administrative assistant, foreign trade) of a state vocational school. The programs of the participants were divided into two categories as social programs and technical programs by taking into consideration the teaching curriculum and the title received after graduation. The number of students studying in the technical programs was 64 and the number of students studying in social programs was 38. The total number of female students was 47 and the number of male students was 55. "The Purdue Visualization of Rotations (ROT) test" was used as a data collection tool in the study. The ROT test consisted of 20 questions. The ROT test was developed by Bodner and Guay (1997). The Turkish translation of the ROT was performed by YIImaz (2012). In order to evaluate the ROT test, the correct answers were scored as 1 , and the wrong and blank answers were scored as 0 . The independent samples t-test and one-way ANOVA test were used to analyze the data.

Results: The spatial ability scores of the students were investigated in terms of the categories of technical and social programs and it was determined that the students who were studying in the technical programs had significantly higher spatial ability scores than the students who were studying social programs. To investigate gender differences in spatial ability, the spatial ability scores of the all the participants were evaluated together and it was seen that there was a significant difference in the spatial ability scores in favor of male participants. When scores were evaluated as technical and social program categories and within themselves, it was seen that there was no significant difference in spatial ability scores in terms of gender. The spatial ability scores of the students were analyzed to determine whether there were any differences among the programs. As a result, it was found that the highest average score belongs to the "Computer Aided Design and Animation" program and there was a statistically significant difference between "Computer Aided Design and Animation" program and "Office Management and Administrative Assistant" program. Additionally, it was found that the average of spatial ability scores was 8.77 for technical programs students, 6.24 for social programs students and 7.82 for all students. The results were compared with similar studies and it was seen that the students of the vocational school did not have enough spatial ability. 


\section{Giriş}

Ülkeler, uluslararası alanda rekabet etme güçlerini artırmak ve sürdürülebilir kalkınma hedeflerine ulaşmak için iş yaşamının ihtiyaç duyduğu yetkin ve nitelikli bireylerin yetiştirilmesine büyük önem vermekte, bu amaç için mesleki ve teknik eğitime yatırımlar yapmaktadır. Türkiye`de mesleki ve teknik eğitim sisteminin önemli bir tamamlayıcısı olan meslek yüksekokulları (MYO), sanayi, ticaret ve hizmet sektörlerinin ihtiyaç duyduğu nitelikli ara elemanlar yetiştirmek amacıyla kurulmuştur (Şahin ve Fındık, 2008). MYO’lar Türkiye'nin rekabet gücünün artırılmasında, özellikle sanayi, ticaret ve hizmet sektörlerinin beklentilerini karşılayacak nitelikli insan gücünün yetiştirilmesinde anahtar bir role sahiptir (Alkan, Suiçmez, Aydınkal ve Şahin, 2014).

Öğrencilerin alanlarında yetkin bireyler olarak yetiştirilmesi mesleki eğitimin önemli hedeflerinden biridir. Yetkinlik, tek başına bilgi ve beceriden daha fazlasını ifade eder (OECD, 2005). Türkiye Yükseköğretim Yeterlilikler Çerçevesi Yönetmelik taslağında beceri, "bilgiyi uygulayabilme, problemleri çözebilme ve görevleri tamamlayabilme yeteneği" olarak tanımlanmışken, yetkinlik ise "bilgiyi, kişisel, sosyal ve/veya metodolojik becerileri iş ve çalışma ortamları ile mesleki ve kişisel gelişim konusunda kullanabilme yeteneği" olarak tanımlanmıştır (YÖK, 2011). Mesleki eğitimde öğrenme, işyerinde veya meslek okullarında yürütülen somut mesleki görevler yardımıyla gerçekleşir, bundan dolayı mesleki eğitimdeki öğrenme sürecinin akademik ortamlardaki öğrenme sürecinden farklı olduğu düşünülür (Baartman ve De Bruijn, 2011). Mesleki eğitimde gerçekleşen öğrenme süreci göz önüne alındığında, MYO`larda yetiştirilen öğrencilerin yetkinlik düzeyleri öğretimin üç bileşenine bağlı olduğu söylenebilir. Bu bileşenler bilgi, beceri ve uygulamadır. MYO ’larda öğrenciler öncelikle alanları ile ilgili teorik bilgileri öğrenirler, sonra alanları ile ilgili gerekli becerileri kazanırlar. Öğrenciler elde ettikleri bilgi ve becerileri, birtakım mesleki görevleri/uygulamaları yerine getirirken birlikte kullanırlar. Böylece öğrenmede kalıcılık sağlanır ve öğrenciler alanlarında yetkin bireyler haline gelirler. Öğrencilerin alanları ile ilgili bilgi ve becerileri kazanma sürecinde sahip oldukları bilişsel özellikleri, başarılarını ve performanslarını etkileyebilmektedir (Danili ve Reid, 2006). Dolayısıyla MYO’larda öğrenim gören öğrencilerin hem okul hem de iş yaşamlarında başarılı olabilmeleri, bir takım bilişsel becerilere sahip olmalarını gerektirmektedir. Özellikle teknik alanlarda çalışanların, mesleki ve akademik yaşamlarında başarılı olabilmeleri için gelişmiş uzamsal yeteneğe sahip olmaları gerekli görülmektedir (Alias, Black ve Gray, 2002; Rafi, Samsudin ve Said, 2008; Sorby, 1999). Uzamsal yetenek, sadece belirli meslek türlerindeki başarılar için değil aynı zamanda günlük yaşam ve okul başarısı için de önemli bir faktör olarak kabul edilmektedir (Yılmaz, 2009).

Alanyazında, uzamsal yetenek ile ilgili birçok tanım bulunmaktadır. Tartre (1990), uzamsal yeteneği, ilişkileri görsel olarak anlama, değiştirme, yeniden düzenleme ve yorumlama ile ilgili zihinsel becerilerin tamamı olarak ifade ederken, Lohman (1996) ise iyi yapılandırılmış görsel imgeleri oluşturma, akılda tutma, imgeler üzerinde düzenleme ve dönüştürme gibi bir takım işlemleri yapabilme yeteneği olarak tanımlamıştır. Çoklu zekâ kuramını ortaya atan Gardner (2011), uzamsal yeteneği zekânın bir türü olarak ele almıştır. Ona göre insan, sekiz farklı zekâ türüne sahiptir ve bunlardan birisi de "uzamsal zekâ"dır. Gardner (2011) ayrıca uzamsal zekânın sorunları çözebilme yeteneğiyle ilişkili olduğunu savunur.

Uzamsal yeteneği etkileyen birçok faktör bulunmaktadır. Bu faktörlerden birisi cinsiyettir (Alias vd., 2002). Eğitim ortamlarında önemli bireysel farklııkların ortaya çıkmasına sebep olabilen (Lubinski, 2010), ayrıca bireyin gelecekteki meslek seçimini de etkileyebilen uzamsal yetenek (Shea, Lubinski ve Benbow, 2001), erkek ve kadın bireyler arasında farklılığın en fazla görüldüğü ve bildirildiği bilişsel özelliklerden biridir. Bu durum uzamsal yetenekte cinsiyet farklılıklarını ve farklılıkların nedenlerini inceleyen birçok çalışmanın yapılmasına neden olmaktadır (örn. Battista, 1990; Bodner ve Guay, 1997; Erkek, Işıksal ve Çakıroğlu, 2017; Hacıömeroğlu ve Hacıömeroğlu, 2017; Turgut ve Yenilmez, 2012). Yapılan araştırmalar incelendiğinde sonuçlarda farklılıklar görülmektedir. Battista (1990), Bodner ve Guay (1997), Erkek vd. (2017), Hacıömeroğlu ve Hacıömeroğlu (2017) tarafından gerçekleştirilmiş çalışmalarda cinsiyet açısından erkek katılımcılar lehine anlamlı farklılığın olduğu bildirilmişken, Turgut ve Nagy-Kondor (2013a, 2013b) ve Turgut ve Yenilmez (2012) tarafından gerçekleştirilmiş çalışmalarda ise cinsiyet açısından anlamlı farklılı̆ın bulunmadığı bildirilmiştir. Linn ve Petersen (1985) tarafından yapılan meta analiz çalışmasında, erkek katılımcılar lehine farklılığın özellikle zihinsel döndürme soruları içeren uzamsal yetenek testlerinde ortaya çıktığı sonucuna ulaşılmıştır. Maeda ve Yoon (2013), uzamsal yetenek testlerinin cevaplandırımasında kısıtlı süre kullanımının kadınlarda erkeklere göre daha fazla kaygıya neden olabileceğini ve bunun sonucu olarak cinsiyet açısından erkeklerin lehine farklılı̆ın ortaya çıkabileceğini ifade etmişlerdir. Bununla birlikte biyolojik, stratejik, deneyimsel ve duygusal faktörler, erkek ve kadınlar arasında uzamsal yetenek farklııklarının ortaya çıkmasına neden olabilmektedir (Maeda ve Yoon, 2013; Moè, 2009). Bu çalışma, seçilen çalışma grubu ve uzamsal yetenekteki cinsiyet farklılıklarını teknik ve sosyal programlar bağlamında incelemesi ile diğer çalışmalardan farklılaşmaktadır. 
Uzamsal yetenek, eğitim ortamlarında genellikle göz ardı edilmektedir (Lubinski, 2010). Oysaki uzamsal yetenek, özellikle teknik alanlarda eğitim gören bireylerin hem okul dönemi hem de mezuniyet sonrası mesleki yaşamlarındaki performanslarını etkileyebilmektedir (Alias vd., 2002; Rafi vd., 2008; Sorby, 1999; Yılmaz, 2009). Dolayısıyla, yeterli bilgi ve beceriyle donanmış, nitelikli ara elemanlar yetiştirmenin amaçlandığı MYO larda öğrenim görmekte olan ve gelecekte mesleki ve teknik alanlarda çalışacak öğrencilerin uzamsal yeteneklerinin incelenmesi önemli bir araştırma konusudur. Yapılan alanyazın araştırması sonucu ulusal alanyazında, MYO öğrencilerinin uzamsal yeteneklerini inceleyen herhangi bir çalışmaya rastlanmamıştır. Uzamsal yetenek ile ilgili gerçekleştirilen ve örneklemi üniversite düzeyindeki öğrenciler olan çalışmalar incelendiğinde, ulusal alanyazındaki çalışmaların genellikle öğretmen adaylarına yönelik gerçekleştirildiği (örn. Erkek vd., 2017; Hacıömeroğlu ve Hacıömeroğlu, 2017; Turgut ve Yenilmez, 2012; Turgut, Yenilmez ve Balbağ, 2017), uluslararası alanyazındaki çalışmaların ise öğretmen adaylarının yanında mühendislik ve fen alanında öğrenim gören lisans öğrencilerine yönelik yürütüldüğü görülmüştür (örn. Bodner ve Guay, 1997; Merchant vd., 2013; Sorby ve Baartmans, 2000). MYO öğrencilerine yönelik gerçekleştirilen bu çalışmanın, ilgili alanyazına katkı sağlayacağı ve bir boşluğu gidereceği düşünülmektedir. Bu çalışmanın amacı, MYO programlarında öğrenim görmekte olan son sınıf öğrencilerinin uzamsal yeteneklerini incelemektir. Çalışmada MYO`nun farklı programlarında öğrenim görmekte olan öğrenciler ele alınmıştır. Bu durumun nedeni teknik ve sosyal olarak sınıflandırılan programlardaki öğrencilerin uzamsal yeteneklerini incelemek ve karşılaştırmaktır. Araştırma problemi, "Meslek yüksekokulu programlarında öğrenim görmekte olan son sınıf öğrencilerinin uzamsal yetenek düzeyleri nedir?" olarak belirlenmiştir. Bu bağlamda, aşağıda belirtilen alt problemler üzerine odaklanılmıştır:

a) Teknik ve sosyal programlarda okuyan öğrencilerin uzamsal yetenek puanlarında anlamlı bir farklıık var mıdır?

b) Cinsiyet değişkeni açısından uzamsal yetenek puanlarında anlamlı bir farklılık var mıdır?

c) Öğrencilerin uzamsal yetenek puanlarında öğrenim gördükleri programlara göre anlamlı bir farklılık var mıdır?

\section{Yöntem}

Araştırmada, nicel araştırma desenlerinden biri olan tarama modeli kullanılmıştır. Tarama modeli, geçmişte ya da halen var olan bir durumu var olduğu gibi betimlemeyi amaçlayan araştırma yaklaşımıdır (Karasar, 2016).

\section{Katılımcilar}

Araştırmanın örneklemini, bir devlet MYO`nun beş farklı programında öğrenim görmekte olan toplam 102 son sınıf öğrencisi oluşturmuştur. Katılımcıların cinsiyet ve öğrenim görülen programa göre dağılım bilgileri Tablo 1 'de verilmiştir. Tablo 1'de görüleceği üzere "bilgisayar destekli tasarım ve animasyon (BDTA)", "bilgisayar teknolojisi (BT)" ve "internet ve ağ teknolojileri (IAT)" programları teknik programlar, "büro yönetimi ve yönetici asistanlığı (BYYA)" ve "dış ticaret (DT)" programları ise sosyal programlar olarak gruplandırılmıştır. Gruplandırmada programın öğretim müfredatı ve mezuniyet sonrası alınan unvan temel alınmıştır.

Tablo 1. Cinsiyete ve öğrenim görülen programa göre katılımcıların sayısı

\begin{tabular}{cccc}
\hline Program & Kadın & Erkek & Toplam \\
\hline BDTA & 10 & 11 & 21 \\
BT & 6 & 14 & 20 \\
IAT & 6 & 17 & 23 \\
Teknik Programlar & 22 & 42 & 64 \\
BYYA & 13 & 3 & 16 \\
DT & 12 & 10 & 22 \\
Sosyal Programlar & 25 & 13 & 38 \\
TOPLAM & 47 & 55 & 102 \\
\hline
\end{tabular}

Tablo 1'de görüleceği üzere, teknik programlarda okuyan öğrencilerin sayısı 64 , sosyal programlarda okuyan öğrencilerin sayısı ise 38 `dir. Toplam kadın öğrenci sayısı 47, erkek öğrenci sayısı ise 55 `tir.

\section{Veri Toplama Aracı}

Araştırmada veri toplama aracı olarak 20 sorudan oluşan "Purdue Uzamsal Görselleştirme: Döndürme (ROT) Testi" kullanılmıştır. ROT testi, orijinali Guay tarafından geliştirilmiş ve 30 sorudan oluşan testin, Bodner ve Guay (1997) tarafından on sorunun testten çıkarılarak elde edilmiş kısa sürümüdür. ROT, çoktan seçmeli sorulardan oluşan bir yetenek testidir. Veri toplama aracının güvenirliği Bodner ve Guay (1997) tarafından 0,78 ile 0,85 arasında olduğu rapor edilmiştir. Testin Türkçe çevirisi Yılmaz (2012) tarafından yapılmıştır. Bir kağıt-kalem testi olan ROT testinin amacı, katılımcıların zihinsel olarak 3B nesnelerin dönüşünü anlama ve zihinsel görselleştirme yeteneklerini ölçmektir. ROT 
testi, uzamsal yeteneği ölçmek amacıyla birçok araştırmada kullanılmıştır (örn. Karaçöp ve Doymuş, 2013; Merchant vd., 2013; Unal, Jakubowski ve Corey, 2009). Yirmi soruluk çoktan seçmeli testin cevaplandırıması için katılımcılara Bodner ve Guay (1997) tarafından önerildiği gibi on dakika süre verilmiştir. Testin uygulanması aynı araştırmacı tarafından gerçekleştirilmiştir. Test ile ilgili örnek soru Şekil 1 `de sunulmuştur.

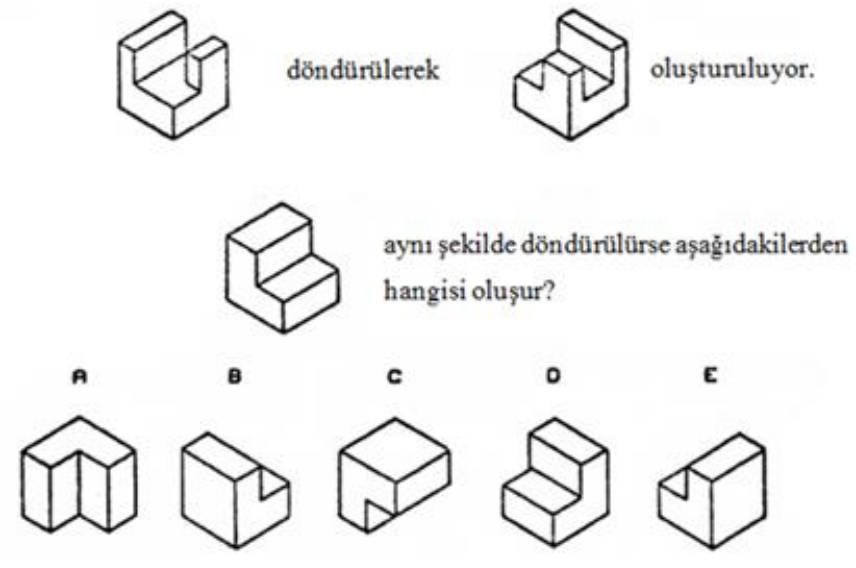

Şekil 1. ROT testinden örnek soru

ROT testindeki her sorunun sadece bir doğru cevabı vardır. ROT testinin değerlendirilmesinde Bodner tarafından gönderilen cevap anahtarı kullanılmış olup doğru cevaplar 1, yanlış ve boş cevaplar 0 şeklinde puanlandırımıştır. Dolayısıyla bu testten alınabilecek en düşük puan 0, en yüksek puan 20`dir.

\section{Veri Analizi}

Öğrencilerin uzamsal yetenek testinden aldıkları puanlar araştırmacılar tarafından hesaplanmış ve elde edilen puanlar SPSS programına aktarılmıştır. Veriler üzerinde kullanılacak istatistiki yöntemlerin belirlenmesi için öncelikle verilerin normal dağılıp dağılmadığı araştırılmıştır. Bu amaçla gruplara ait puanların çarpıklık katsayıları $(-1+1$ arası) incelenmiş (Büyüköztürk, 2017) ve verilerin normal dağılım gösterdiği belirlenmiştir. Gruplara ait puanların çarpıklık katsayıları Tablo 2 'de gösterilmiştir. Veri analizi için bağımsız gruplar $t$-testi ve tek yönlü ANOVA testi kullanılmıştır.

\section{Tablo 2. Gruplara ait puanların çarpıklık katsayıları}

\begin{tabular}{cc}
\hline Grup & Çarpıklık Katsayısı \\
\hline BDTA & 0,43 \\
BT & 0,54 \\
IAT & $-0,41$ \\
Teknik Programlar & 0,35 \\
\hline BYY & 0,78 \\
DT & 0,24 \\
Sosyal Programlar & 0,45 \\
\hline Kadın & 0,82 \\
Erkek & 0,37 \\
\hline
\end{tabular}

\section{Bulgular}

Çalışmada öğrencilerin uzamsal yeteneklerini belirlemek amacıyla ROT testi uygulanmıştır. Veri toplama aracından elde edilen uzamsal yetenek puanlarının öğrencilerin öğrenim gördükleri programlara göre ortalamaları Tablo 3 `te gösterilmiştir. 
Tablo 3. Programlara göre uzamsal yetenek puan ortalamaları

\begin{tabular}{cc}
\hline Programlar & Ortalama \\
\hline BDTA & 9,62 \\
BT & 8,1 \\
IAT & 8,57 \\
Teknik Programlar & 8,77 \\
\hline BYYA \\
DT & 5,88 \\
Sosyal Programlar & 6,5 \\
TOPLAM & 6,24 \\
\hline
\end{tabular}

Tablo 3 `te görüldüğü gibi uzamsal yetenek testinden alınan en yüksek puan ortalaması, BDTA programında okuyan öğrencilere aittir $(\bar{x}=9,62)$. Teknik programlarda okuyan öğrencilerin uzamsal yetenek puan ortalaması $(\bar{x}=8,77)$ sosyal programlarda okuyan öğrencilerin puan ortalamasından $(\bar{x}=6,24)$ daha yüksektir. Öğrencilerin tamamı değerlendirildiğinde testten alınan puanların ortalamasının 7,82 olduğu tespit edilmiştir. Her bir program için erkek öğrencilerin puan ortalamaları kadın öğrencilerin puan ortalamalarından daha yüksek olduğu belirlenmiştir.

Teknik ve sosyal programlarda öğrenim gören öğrencilerin uzamsal yetenek puanları arasında istatistiki olarak anlamlı bir farklılığın olup olmadığını incelemek için bağımsız gruplar $t$-testi gerçekleştirilmiş ve sonuçları Tablo 4 `te verilmiştir.

Tablo 4. Teknik ve sosyal programlarda öğrenim gören öğrencilerin uzamsal yetenek puanlarına ilişkin bağımsız gruplar t-testi sonuçları

\begin{tabular}{ccccccc}
\hline Grup & N & $\overline{\mathbf{x}}$ & ss & sd & t & p \\
\hline Teknik Programlar & 64 & 8,77 & 4,03 & 100 & 3,30 &, 001 \\
Sosyal Programlar & 38 & 6,24 & 3,21 & & & \\
\hline
\end{tabular}

Tablo 4`e göre teknik ve sosyal programlarda öğrenim gören öğrencilerin uzamsal yetenek puanları arasında teknik programlarda öğrenim gören öğrenciler lehine istatistiki olarak anlamlı bir farklılık vardır $(t=3,30 ; p<, 01)$.

Uzamsal yetenek puanlarını cinsiyet değişkenine göre incelemek amacıyla bağımsız gruplar $t$-testi kullanılmıştır. Erkek ve kadın öğrencilerin testten aldıkları puanlar arasında istatistiksel olarak anlamlı bir farklılığın olup olmadığını belirlemek için gerçekleştirilen bağımsız gruplar $t$-testi sonuçları Tablo 5 te sunulmuştur.

Tablo 5. Cinsiyete göre uzamsal yetenek puanlarına ilişkin bağımsız gruplar $t$-testi sonuçları

\begin{tabular}{|c|c|c|c|c|c|c|c|}
\hline Grup & Cinsiyet & $\mathbf{N}$ & $\overline{\boldsymbol{x}}$ & ss & $s d$ & $t$ & $p$ \\
\hline \multirow{2}{*}{ Teknik Programlar } & Kadın & 22 & 7,82 & 4,33 & \multirow{2}{*}{62} & \multirow{2}{*}{1,372} & \multirow{2}{*}{ 175 } \\
\hline & Erkek & 42 & 9,26 & 3,82 & & & \\
\hline \multirow{2}{*}{ Sosyal Programlar } & Kadın & 25 & 5,76 & 3,33 & \multirow{2}{*}{36} & \multirow{2}{*}{1,28} & \multirow{2}{*}{ 208 } \\
\hline & Erkek & 13 & 7,15 & 2,85 & & & \\
\hline \multirow{2}{*}{ TOPLAM } & Kadın & 47 & 6,72 & 3,93 & \multirow{2}{*}{100} & \multirow{2}{*}{2,698} & \multirow{2}{*}{,008 } \\
\hline & Erkek & 55 & 8,76 & 3,70 & & & \\
\hline
\end{tabular}

Tablo 5 `e göre öğrencilerin tamamı birlikte değerlendirildiğinde uzamsal yetenek puanlarında cinsiyet açısından erkek öğrenciler lehine anlamlı bir farklılığın olduğu görülmüştür $(t=2,698 ; p<, 01)$. Ancak teknik ve sosyal programlar kendi içlerinde değerlendirildiğinde cinsiyet yönünden anlamlı bir farklılık görülmemiştir $(t=1,372 ; p>, 05, t=1,28$; $p>, 05)$.

Öğrencilerin öğrenim gördükleri programlar açısından uzamsal yetenek puanlarında anlamlı bir farklılığın olup olmadığını incelemek için ANOVA testi kullanılmıştır. ANOVA testi gerçekleştirilmeden önce varsayımların sağlanıp sağlanmadığı incelenmiştir. Gerçekleştirilen Levene testi sonucunda varyansların homojenliği şartının sağlanamadığı $(p<, 05)$ görülmüş, bu sebeple puanlar üzerinde karekök dönüştürme işlemi yapılmıştır (Field, 2009). Varsayımlar sağlandıktan sonra ANOVA analizi, bir post-hoc testi olan Bonferroni testi ile gerçekleştirilmiştir. Analiz sonuçları Tablo 6 'da sunulmuştur. 
Tablo 6. Öğrencilerin uzamsal yetenek puanlarının öğrenim gördükleri programlara göre ANOVA sonuçları

\begin{tabular}{ccccccr}
\hline $\begin{array}{c}\text { Varyansın } \\
\text { Kaynağı }\end{array}$ & Kareler Toplamı & sd & Kareler Ortalaması & F & p & Anlamlı Farklılık \\
\hline Gruplararası & 5,934 & 4 & 1,484 & & & \\
Gruplariçi & 48,981 & 97 &, 505 & 2,938 &, 024 & BDTA - BYYA \\
Toplam & 54,916 & 101 & & & & \\
\hline
\end{tabular}

Tablo 6 ya göre en yüksek uzamsal yetenek puan ortalamasına sahip BDTA programı $(\bar{x}=9,62)$ ile en düşük puan ortalamasına sahip BYYA programı $(\bar{x}=5,88)$ arasında istatistiki olarak anlamlı bir farklılık bulunmuştur $F(4,97)=2,94$; $p<, 05$. Bunun dışında diğer programlar arasında anlamlı bir farklılığa rastlanmamıştır.

\section{Tartışma}

İyi yapılandırılmış görsel imgeleri oluşturma, akılda tutma, imgeler üzerinde düzenleme ve dönüştürme işlemi yapabilme yeteneği olan uzamsal yetenek, birçok teknik meslekte başarıyı etkileyebilen önemli bir faktördür (Lohman, 1996). Bu çalışmada, MYO programlarında öğrenim görmekte olan son sınıf öğrencilerinin uzamsal yetenekleri program ve cinsiyet değişkenlerine göre incelenmiştir. Çalışma sonunda teknik programlarda öğrenim gören öğrencilerin uzamsal yetenek testinden aldıkları puanların sosyal programlarda öğrenim gören öğrencilere göre daha yüksek olduğu görülmüştür. Erkek vd. (2017) ilköğretim matematik, fen bilgisi ve okul öncesi öğretmenlik programlarında öğrenim gören öğrencilerin uzamsal yeteneklerini incelemiş ve en yüksek puana sırasıyla ilköğretim matematik, fen bilgisi ve okul öncesi öğretmenlik programı öğrencilerinin sahip olduğu sonucuna ulaşmışlardır. Başka bir deyişle, Erkek vd. (2017) sayısal ağırlıklı ilköğretim matematik ve fen bilgisi öğretmenliği programlarında öğrenim gören öğrencilerin sözel ağırlıklı okul öncesi öğretmenliği programında öğrenim gören öğrencilere göre daha yüksek uzamsal yetenek puanına sahip olduğunu tespit etmişlerdir. Dolayısıyla çalışmanın bu sonucu Erkek vd. (2017) tarafından yapılan çalışmanın sonucuyla uyumludur.

Teknik programlarda okuyan öğrencilerin uzamsal yetenek testinden aldıkları puanların sosyal programlarda okuyan öğrencilere göre daha yüksek olmasının nedeni teknik programlarda öğrenim gören öğrencilerin, müfredatlarının bir sonucu olarak uzamsal yeteneklerini geliştirecek öğretimsel etkinliklere (örn. matematik/geometri, grafik, animasyon, çizim ve modelleme) daha fazla maruz kalması olabilir. Bir diğer neden ise, teknik programlar olarak sınıflandırılan BT ve İAT programlarında öğrenim gören öğrencilerin büyük bir çoğunluğunun meslek liselerinin bilişim teknolojileri alanından mezun öğrenciler olması ve dolayısıyla teknik resim dersi almış olmaları olabilir. Meslek liselerinin bilişim teknolojileri alanında 10. sınıf dersleri içerisinde "Bilişim Teknik Resmi" dersi yer almaktadır (MEB, 2018). Teknik resim dersi öğrencilerin uzamsal yeteneklerini geliştirmede etkili bir derstir (Sorby, 1999). Uzamsal yetenek testinden en yüksek puana sahip olan programın BDTA programı olduğu tespit edilmiştir. Ayrıca programlar arasında sadece BDTA programı ile BYYA programı arasında istatistiki olarak anlamlı bir farklılık bulunmuştur. BDTA programının amacı, öğrencilere bilgisayar destekli iki boyutlu ve üç boyutlu tasarım ve modelleme programlarının kullanımını öğretmek, tasarım ve modelleme için gerekli yetkinlikleri kazandırmaktır. BDTA programında tasarım ve modelleme ile ilgili dersler hem birinci hem de ikinci sınıf ders planında yer almaktadır. Tasarım ve modelleme etkinliklerinin öğrencilerin uzamsal yeteneklerini geliştirmede etkili olması (Kösa ve Karakuş, 2018; Šafhalter, Vukman ve Glodež, 2016; Toptaş, Çelik ve Karaca, 2012) bu dersleri görmekte olan BDTA programındaki öğrencilerin uzamsal yetenek testinden daha yüksek puan almasının nedeni olabilir.

Cinsiyet, uzamsal yetenek ile ilgili araştırmalarda en fazla incelenen değişkenlerden biridir. Ancak yapılan araştırmaların sonuçları çoğu zaman birbirleriyle çelişmektedir. Çoğu çalışmada uzamsal yetenek puanlarında erkek katılımcılar lehine sonuçlar elde edilmişken (Battista, 1990; Bodner ve Guay, 1997; Erkek vd., 2017) bazılarında ise cinsiyet açısından anlamlı bir farklılı̆ıın görülmediği (Turgut ve Nagy-Kondor, 2013a, 2013b; Turgut ve Yenilmez, 2012) bildirilmiştir. Uzamsal yetenek ile ilgili cinsiyet farklııkları sıklıkla zihinsel döndürme testlerinde ortaya çıkmaktadır (Linn ve Petersen, 1985). Bu çalışmada ise tüm öğrencilerin uzamsal yetenek puanları birlikte değerlendirildiğinde cinsiyet açısından erkeklerin lehine anlamlı bir farklııı̆ın olduğu görülmüştür. Benzer şekilde, Erkek vd. (2017) ilköğretim matematik, fen bilgisi ve okul öncesi öğretmen adaylarından oluşan katılımcıların uzamsal yeteneklerini cinsiyet açısından incelemişler ve erkek katılımcılar lehine anlamlı farklılığın olduğunu tespit etmişlerdir. MYO'da yer alan teknik ve sosyal programlar kendi içlerinde bağımsız olarak değerlendirildiğinde ise, erkek öğrencilerin kadın öğrencilerden daha yüksek uzamsal yetenek puanlarına sahip olmalarına rağmen bu farklılıkların istatistiki olarak anlamlı olmadığı görülmüştür. Diğer bir deyişle gruplar daha homojen ve benzer olduğunda cinsiyet açısından anlamlı bir farklılık çıkmamıştır. Benzer şekilde, Turgut ve Yenilmez (2012) ilköğretim ve ortaöğretim matematik öğretmeni

(Kastamonu Eğitim Dergisi, 28(2), 2020) 
adaylarının uzamsal yeteneklerini inceledikleri çalışmalarında puanlarda cinsiyet açısından anlamlı bir farklılı̆ın olmadığı sonucuna ulaşmışlardır. Turgut ve Yenilmez (2012) in araştırmasında yer alan katılımcıların tamamı matematik öğretmeni adaylarıdır. Turgut ve Nagy-Kondor (2013a, 2013b) tarafından yapılan çalışmalarda ise Türk ve Macar ilköğretim matematik öğretmeni adaylarının uzamsal yetenekleri incelenmiş ve uzamsal yetenek puanlarında cinsiyet açısından anlamlı bir farklılı̆ın görülmediği rapor edilmiştir. Turgut ve Nagy-Kondor (2013a, 2013b) tarafından gerçekleştirilen çalışmalarda katılımcıların tamamı matematik öğretmeni adaylarıdır.

Alias vd. (2002) kadın ve erkek öğrencilerin benzer uzamsal deneyimlere sahip olmalarının, uzamsal yeteneklerde cinsiyet açısından fark çıkmamasına neden olabileceğini belirtmişlerdir. Richardson (1994) uzamsal yetenekteki cinsiyet farklılıklarının öğretimsel deneyimlerle ortadan kaldırılabileceğini savunur. Cherney ve Neff (2004) bilgisayar ve video oyunları gibi uzamsal görevlere maruz kalmanın uzamsal yetenek performansını olumlu yönde etkileyebileceğini ifade eder. Bu çalışmada MYO'daki öğrencilerin tamamı birlikte değerlendirildiğinde cinsiyet açısından anlamlı farklılığın ortaya çıkmasında öğrencilerin öğrenim gördükleri programları, dolayısıyla öğrenim geçmişleri ve uzamsal deneyimleri etkili olmuş olabilir. Bu durumda, cinsiyet faktörünün uzamsal yetenek üzerindeki etkisini incelemeyi amaçlayan araştırmalarda örneklem olarak, aynı sınıf düzeyinde bulunan, benzer öğrenim yaşantısına sahip, erkek ve kadın katıımcı sayısının eşit olduğu bir çalışma grubunun seçilmesinin, sonuçlar üzerinde daha doğru değerlendirmelerin yapılmasına katkı sağlayabileceği söylenebilir.

Bu araştırmada uzamsal yeteneği ölçmek için ROT testi kullanılmıştır. Testin cevaplandırılması için öğrencilere on dakika süre verilmiştir. Uygulanan ROT testi sonucu meslek yüksekokulu öğrencilerinin uzamsal yetenek puanları tespit edilmiştir. Elde edilen sonuçlar, uzamsal yeteneği ölçmek için ROT testinin kullanıldığı ve testin cevaplandırılması için katılımcılara on dakikalık sürenin verildiği Karaçöp ve Doymuş (2013), Merchant vd. (2013) ve Unal vd. (2009)'nin çalışmalarıyla karşılaştırılmıştır. Karaçöp ve Doymuş (2013) birinci sınıf fen bilgisi öğretmen adaylarının, Merchant vd. (2013) kimya dersini alan üniversite öğrencilerinin, Unal vd. (2009) ise matematik öğretmen adaylarının uzamsal yeteneklerini ROT testini kullanarak ölçmüşlerdir. Bu çalışmada uzamsal yetenekleri incelenen MYO öğrencilerinin ROT testinden aldıkları puanların ortalaması, Karaçöp ve Doymuş (2013), Merchant vd. (2013) ve Unal vd. (2009) tarafından gerçekleştirilen çalışmalarda rapor edilen değerlerden daha düşük olduğu görülmüştür. Özellikle bu puan farkı sosyal programlar için daha fazladır.

Ülkelerin rekabet etme güçleri yeterli bilgi ve beceriyle donanmış nitelikli bireylerin sayısıyla ilişkilidir. Bu durum mesleki ve teknik eğitimin önemini artırmakta, mesleki eğitimde başarının artırılması için daha fazla bilimsel çalışmanın yapılmasını gerekli kılmaktadır. Dolayısıyla meslek yüksekokullarında öğrenim gören öğrencilerin hem mesleki hem de gündelik yaşamlarını etkileyebilecek önemli bir faktör olan uzamsal yeteneklerini incelemek ve geliştirmek önem arz etmektedir. Bu açıdan tasarım, çizim, grafik ve modelleme gibi uzamsal yetenek gelişimini olumlu yönde etkileyebilecek eğitim ve etkinliklerin MYO müfredatlarına eklenmesi öğrenci yeteneklerinin gelişimine katkı sağlayabilecektir. Meslek yüksekokullarında öğrenim gören öğrencilerin başarılarını artıracak ve onları alanlarında yetkin bireyler haline getirecek fırsatların sunulması, hem ülke ekonomisine katkı sağlayacak hem de ülkemizin uluslararası alanda rekabet etme gücünü artıracaktır. Bu nedenle MYO öğrencilerine yönelik eğitim araştırmalarının sayısının artırılması önem arz etmektedir.

\section{Sonuç}

Uzamsal yetenek, mesleki ve teknik eğitimde başarılı olabilmek için önemli görülen bilişsel bir özelliktir. Bu çalışmada MYO son sınıf öğrencilerinin uzamsal yetenekleri, program ve cinsiyet değişkenlerine göre incelenmiştir. Araştırma sonunda aşağıdaki sonuçlara ulaşılmışır:

- Teknik programlarda öğrenim gören öğrencilerin uzamsal yetenek testinden aldıkları puanlar sosyal programlarda öğrenim gören öğrencilere göre anlamlı olarak daha yüksektir.

- Teknik ve sosyal programlar kendi içlerinde bağımsız olarak değerlendirildiğinde uzamsal yetenek puanlarında cinsiyet açısından anlamlı bir farklılık görülmemiştir.

- Uzamsal yetenek testinden alınan en yüksek puan ortalaması bilgisayar destekli tasarım ve animasyon programına aittir.

- Meslek yüksekokulu son sınıf öğrencilerinin uzamsal yetenek puanları yeterli düzeyde değildir. 


\section{Kaynakça}

Alias, M., Black, T. R., \& Gray, D. E. (2002). Effect of instructions on spatial visualization ability in civil engineering students. International Education Journal, 3(1), 1-12.

Alkan, R. M., Suiçmez, M., Aydınkal, M., \& Şahin, M. (2014). Meslek yüksekokullarındaki mevcut durum: Sorunlar ve bazı çözüm önerileri. Yüksekögretim ve Bilim Dergisi, 4(3), 133-140.

Baartman, L. K., \& De Bruijn, E. (2011). Integrating knowledge, skills and attitudes: Conceptualising learning processes towards vocational competence. Educational Research Review, 6(2), 125-134.

Battista, M. T. (1990). Spatial visualization and gender differences in high school geometry. Journal for Research in Mathematics Education, 21(1), 47-60.

Bodner, G. M., \& Guay, R. B. (1997). The Purdue Visualization of Rotations Test. The Chemical Educator, 2(4), 1-17.

Büyüköztürk, Ş. (2017). Sosyal bilimler için veri analizi el kitabı (23. Baskı). Ankara: Pegem Akademi.

Cherney, I. D., \& Neff, N. L. (2004). Role of strategies and prior exposure in mental rotation. Perceptual and Motor Skills, 98, 1269-1282.

Danili, E., \& Reid, N. (2006). Cognitive factors that can potentially affect pupils' test performance. Chemistry Education Research and Practice, 7(2), 64-83.

Erkek, Ö., Işıksal, M., \& Çakıroğlu, E. (2017). A study on pre-service teachers' spatial visualization ability and spatial anxiety. Kastamonu Eğitim Dergisi, 25(1), 33-50.

Field, A. (2009). Discovering statistics using SPSS (3rd Edition). London: Sage Publication.

Gardner, H. (2011). Frames of mind: The theory of multiple intelligences. New York: Basic Books.

Hacıömeroğlu, G., \& Hacıömeroğlu, E. S. (2017). Cinsiyet, uzamsal beceri, mantıksal düşünme becerisi ve çözüm tercihleri arasındaki ilişkinin incelenmesi. Adıyaman Üniversitesi Eğitim Bilimleri Dergisi, 7(1), 116-131.

Karaçöp, A., \& Doymuş, K. (2013). Effects of jigsaw cooperative learning and animation techniques on students' understanding of chemical bonding and their conceptions of the particulate nature of matter. Journal of Science Education and Technology, 22(2), 186-203.

Karasar, N. (2016). Bilimsel araştırma yöntemi: Kavramlar, ilkeler, teknikler (31. Basım), Ankara: Nobel Akademik Yayıncilık.

Kösa, T., \& Karakuş, F. (2018). The effects of computer-aided design software on engineering students' spatial visualisation skills. European Journal of Engineering Education, 43(2), 296-308.

Linn, M. C., \& Petersen, A. C. (1985). Emergence and characterization of sex differences in spatial ability: A metaanalysis. Child Development, 56, 1479-1498.

Lohman, D. F. (1996). Spatial ability and G. (I. Dennis ve P. Tapsfield, Editör). Human abilities: Their nature and measurement içinde (s. 97-116). Mahwah, NJ: Erlbaum.

Lubinski, D. (2010). Spatial ability and STEM: A sleeping giant for talent identification and development. Personality and Individual Differences, 49(4), 344-351.

Maeda, Y., \& Yoon, S. Y. (2013). A meta-analysis on gender differences in mental rotation ability measured by the Purdue spatial visualization tests: Visualization of rotations (PSVT: R). Educational Psychology Review, 25(1), 69-94.

MEB. (2018). Bilişim teknolojileri alanı haftalık ders çizelgesi. http://www.megep.meb.gov.tr/dokumanlar/10.SINIF (2018-2019)/10 HDÇ/BiLişiM TEKNOLOJiLERi_HDÇ_10.PDF adresinden erişildi.

Merchant, Z., Goetz, E. T., Keeney-Kennicutt, W., Cifuentes, L., Kwok, O. M., \& Davis, T. J. (2013). Exploring 3-D virtual reality technology for spatial ability and chemistry achievement. Journal of Computer Assisted Learning, 29(6), 579-590. 
Moè, A. (2009). Are males always better than females in mental rotation? Exploring a gender belief explanation. Learning and Individual Differences, 19(1), 21-27.

OECD. (2005). The definition and selection of key competencies. Executive summary. https://www.oecd.org/pisa/35070367.pdf adresinden erişildi.

Rafi, A., Samsudin, K. A., \& Said, C. S. (2008). Training in spatial visualization: The effects of training method and gender. Journal of Educational Technology \& Society, 11(3), 127-140.

Richardson, J. T. (1994). Gender differences in mental rotation. Perceptual and Motor Skills, 78(2), 435-448.

Šafhalter, A., Vukman, K. B., \& Glodež, S. (2016). The effect of 3D-modeling training on students' spatial reasoning relative to gender and grade. Journal of Educational Computing Research, 54(3), 395-406.

Shea, D.L., Lubinski, D., \& Benbow, C.P. (2001). Importance of assessing spatial ability in intellectually talented young adolescents: A 20-year longitudinal study. Journal of Educational Psychology, 93(3), 604-614.

Sorby, S. A. (1999). Developing 3-D spatial visualization skills. Engineering Design Graphics Journal, 63(2), 21-32.

Sorby, S. A., \& Baartmans, B. J. (2000). The development and assessment of a course for enhancing the 3-D spatial visualization skills of first year engineering students. Journal of Engineering Education, 89(3), 301-307.

Şahin, i., \& Fındık, T. (2008). Türkiye'de mesleki ve teknik eğitim: Mevcut durum, sorunlar ve çözüm önerileri. Türkiye Sosyal Araştırmalar Dergisi, 12(3), 65-86.

Tartre, L. A. (1990). Spatial orientation skill and mathematical problem solving. Journal for Research in Mathematics Education, 21(3), 216-229.

Toptaş, V., Çelik, S., \& Karaca, E. T. (2012). Improving 8th grades spatial thinking abilities through a 3D modeling program. The Turkish Online Journal of Educational Technology (TOJET), 11(2), 128-134.

Turgut, M., \& Nagy-Kondor, R. (2013a). Comparison of Hungarian and Turkish prospective mathematics teachers' mental cutting performances. Acta Didactica Universitatis Comenianae, 13, 47-58.

Turgut, M., \& Nagy-Kondor, R. (2013b). Spatial visualization skills of Hungarian and Turkish prospective mathematics teachers. International Journal for Studies in Mathematics Education, 6(1), 168-183.

Turgut, M., \& Yenilmez, K. (2012). Matematik öğretmeni adaylarının uzamsal görselleştirme becerileri. Eğitim ve Öğretim Araştırmaları Dergisi, 1(2), 243-252.

Turgut, M., Yenilmez, K., \& Balbağ, M. Z. (2017). Öğretmen adaylarının mantıksal ve uzamsal düşünme becerileri: Bölüm, cinsiyet ve akademik performansın etkisi. Mehmet Akif Ersoy Üniversitesi Eğitim Fakültesi Dergisi, 1(41), 265-283.

Unal, H., Jakubowski, E., \& Corey, D. (2009). Differences in learning geometry among high and low spatial ability preservice mathematics teachers. International Journal of Mathematical Education in Science and Technology, 40(8), 997-1012.

Yılmaz, H. B. (2009). On the development and measurement of spatial ability. International Electronic Journal of Elementary Education, 1(2), 83-96.

Yılmaz, T. (2012). Bilgisayar tabanlı modellemenin ve fiziksel modellemenin 9. sınıf öğrencilerinin uzamsal yeteneklerine ve iyonik bileşiklerin kristal yapılarını kavrama düzeylerine etkilerinin karşılaştııılması. Yayımlanmamış yüksek lisans tezi, Boğaziçi Üniversitesi, İstanbul.

YÖK. (2011). Türkiye Yükseköğretim Yeterlilikler Çerçevesi. http://tyyc.yok.gov.tr/dosyalar/21122011TYYC\%20Yonetmeligi-Taslak.doc adresinden erişildi. 